\title{
Federal panel aims to improve health care
}

$\mathrm{T}$ wo leading Canadian physicianresearchers will serve on a new blue-ribbon panel designed to identify and recommend innovations in health care that the federal government can support and that won't cost taxpayers any additional money.

Dr. David Naylor, former president of the University of Toronto, will chair the federal Advisory Panel on Healthcare Innovation. As a member of a previous panel that reviewed federal support for research and development, and as chair of the now-defunct National Advisory Committee on SARS and Public Health, Naylor is considered a heavy-hitter in medical, research and public policy.

The other seven panel members include researcher Dr. Cyril Frank, CEO of Alberta Innovates Health Solutions, as well as Francine Girard, a nurse and dean of the Faculty of Nursing Sciences at the Université de Montréal, and nurse Chris Power, president and CEO of Capital Health in Halifax. The other board members, including Heather Reisman, the founder and CEO of Indigo, have business, economic and public policy backgrounds.

In announcing the panel, federal Health Minister Rona Ambrose said she has seen examples of world-leading innovation in the Canadian health care system. She is concerned, however, about how Canada will address the needs of its aging population, how the health care system copes with chronic conditions and whether expensive new technologies actually improve the quality of care.

"It is clear to me that when we speak about health care, we owe it to Canadians to consider its economics: how we finance, organize and deliver the quality care Canadians need," Ambrose said at the Li Ka Shing Knowledge Institute of St. Michael's in Toronto, where the panel held its first meeting on June 24.

Canada's total spending on health care currently stands at $11.2 \%$ of its gross domestic product, the fifthhighest among member countries of the Organisation for Economic Co-operation and Development. Ambrose said actual health care spending (when adjusted for inflation), doubled between 1975 and 2011 in Canada.

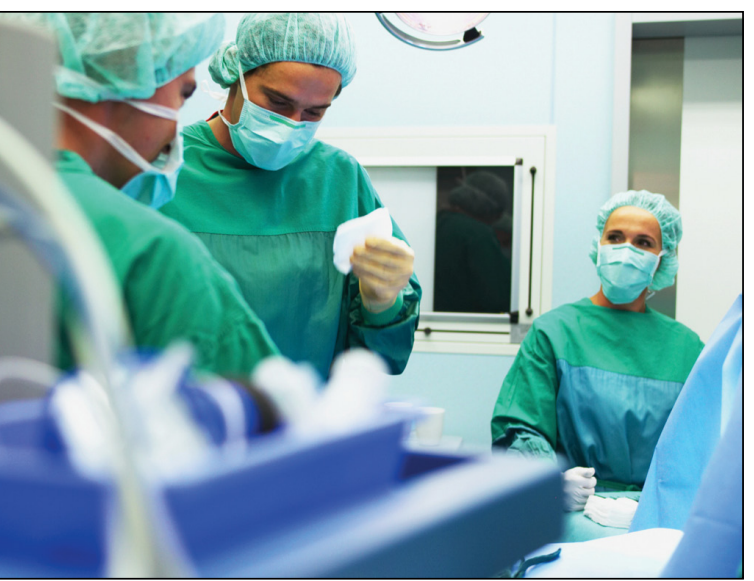

The new Advisory Panel on Healthcare Innovation is charged with finding ways to improve health care for Canadians without increasing the overall costs.

"I am committed to finding ways to harness the tremendous potential of innovation in health care, to make better use of our existing resources, and to achieve an efficient, more responsive and financially sustainable health system for the long term," Ambrose said.

She has asked the panel to identify five areas of innovation, both in Canada and internationally, that hold the greatest promise to reduce the growth in health care spending in a sustainable manner, while leading to improvements in the quality and accessibility of health care.

Ambrose offered only general examples of the types of innovation the panel might consider, such as "industry partnering with the health care community to develop new technologies or software programs, to doctors and other health care providers collaborating in new ways to provide integrated, patient-centred care."

A leading health policy analyst says that while the panel offers a welcome focus on innovation and demonstrates the federal government's role in the health care system, Canada's larger need is to implement the innovations that have already been demonstrated.

"We already have enough evidence on how to do a lot of things better," says Dr. Michael Rachlis, author of Prescription for Excellence. He points out that if more physicians, for example, were to implement a scheduling model called advanced access, they could not only ensure most patients are seen the day they need treatment, but would also be able to take on additional patients.

The panel's terms of reference require that the innovation be evidence-based and fiscally responsible, and consistent with the core principles of the Canada Health Act. It will recommend five ways the federal government can advance innovation in the five critical areas that it will identify. An interim report is expected in January 2015, with the final report due in May 2015, before the next federal election.

Naylor and his colleagues must make sure, however, that anything they recommend "must not imply either an increase or a decrease in the overall level of federal funding for current initiatives supporting innovation in health care. The recommendations must also not result in increasing spending pressure on provincial and territorial budgets," the panel's terms of reference state.

Ambrose has also asked the panel to consult with the provinces and territories, and to consider the perspectives of patients and consumers, innovators and entrepreneurs, health system "stakeholders," First Nations people, businesses and industry representatives. "This will be an open process where all views are welcome," she said. — Laura Eggertson, Ottawa, Ont.

CMAJ 2014. DOI:10.1503/cmaj.109-4840 